\title{
Exploration and Innovative Practice of Engineering Science Popularization Education Model in Xinjiang Universities
}

\author{
Yan $\mathrm{Ma}^{1,{ }^{1}}$ Wenjing Teng ${ }^{2}$ Lijuan $\mathrm{Jin}^{3}$ \\ ${ }^{l}$ School of Chemistry and Environmental Engineering, Xinjiang Institute of Engineering, Urumqi, Xinjiang, \\ China \\ ${ }^{2}$ Engineering Training Center, Xinjiang University, Urumqi, Xinjiang, China \\ ${ }^{3}$ Office of Academic Research, Xinjiang University, Urumqi, Xinjiang, China \\ *Corresponding author. Email:903432304@qq.com
}

\begin{abstract}
Colleges and universities are important bases for scientific and technological innovation and the main force in the implementation of science and education to rejuvenate the country. They have gathered numerous scientific research resources and popular science resources, and have played an important role in popularizing scientific knowledge and promoting scientific literacy of the general public. This article summarizes and analyzes the status quo of science popularization activities in the field of engineering science in Xinjiang colleges and universities, researches and explores new paths for engineering science popularization education and practice, and further improves the ability of engineering science popularization, with a view to serving and improving the public's scientific quality.
\end{abstract}

Keywords: Science popularization in colleges and universities, Education model, Exploration, Innovative practice.

\section{INTRODUCTION}

Since the "Law of the People's Republic of China on the Popularization of Science and Technology" was promulgated and implemented in 2002, science popularization activities have become a basic project for continuously enhancing national innovation capabilities and international competitiveness. It has played an important role in popularizing scientific knowledge, advocating scientific methods, disseminating scientific ideas, and promoting scientific spirit. The "National Medium and Longterm Educational Reform and Development Plan (2010-2020)" takes implementing scientific popularization work, and improving the public's scientific and humanistic quality as one of the important contents of the social capabilities of colleges and universities. In October 2020, the

*Project: 2020 Autonomous Region Major Science Popularization Activity Plan Project "Practice of Youth Science Popularization Based on Advanced Manufacturing" (2060702).

CLC Code: N4 Document

Identification Code: A
Ministry of Education pointed out in its response to recommendation No. 2027 of the Third Session of the Thirteenth National People's Congress that it is necessary to supervise and urge colleges and universities to strengthen science popularization work, and the Ministry of Education supports encouraging colleges and universities to rely on laboratory resources to apply for science popularization bases, combine their own scientific research advantages, and strengthen science popularization capabilities. Xinjiang colleges and universities take science popularization services as their responsibilities, carry out social science popularization work through various methods and channels. They play an increasingly important role in the field of science popularization, and play an irreplaceable important role. Also, they demonstrate scientific and technological innovation achievements in popular science education, and improve their social service capabilities. Against the background of the new era, how Xinjiang universities can make use of the advantages of engineering science popularization 
resources, fully reflect the characteristics of engineering professions, and make science popularization practice more grounded, are the issues worthy of exploration and research.

\section{THE STATUS QUO OF SCIENCE POPULARIZATION EDUCATION IN COLLEGES AND UNIVERSITIES}

\subsection{Carrying out Thematic Activities}

Engineering is the application of basic science principles such as mathematics, physics and chemistry combined with technical experience accumulated in production practice. The research and practice activities of "new engineering" are more closely integrated with popular science practices, and they have more professional characteristics. Colleges and universities in Xinjiang launched popular science exhibitions, publicity visits, and public welfare lectures related to the theme through science popularization activity months, science popularization weeks, and science open days, to advocate the good social customs of stressing science, loving science, learning science, and using science, and practically implement "science changes life, science popularization improves quality". Among them, during the popular science open days, young people inside and outside the school are organized to enter laboratories and engineering research centers to study and visit, and participate in the production of scientific and technological works through hands-on practice, so that young people can understand the most cutting-edge science and technology, feel the charm of advanced engineering culture to improve their engineering literacy, and stimulate the motivation and vitality of young people to participate in innovation and have the courage to innovate.

\subsection{Holding Science Popularization Summer Camp Activities}

Science popularization summer camp is an emerging activity that combines cutting-edge technology and modern educational wisdom. It can achieve interdisciplinary integration. Due to the concentration of time, a variety of science popularization activities can be carried out systematically. Xinjiang colleges and universities rely on the existing science popularization base to carry out popular science summer camp activities, and receive visits by young people in the area. Through various forms such as explanations, demonstrations, observation and thinking, VR experiences, etc., young people can understand popular science knowledge, improve scientific cognition, broaden engineering vision, and exercise team cooperation ability, thinking ability and practical ability, which have played a positive role in demonstrating and leading in giving full play to the function of science popularization and enhancing the influence of science popularization base. At the same time, it actively opens tours to young people from Central Asian countries, promotes the spirit of Chinese craftsmen, and promotes interactive exchanges among young people from China and foreign countries and regions.

\subsection{The Integration of Science Popularization and Education}

Xinjiang colleges and universities take advantage of their own educational resources, copy the model of science and technology museums, effectively combine engineering practice teaching, ideological and political education, and popular science practice, and organize various "practical education" activities for college students inside and outside the school, including "nationalities unite as one family and help each other to practice skills", "connotative development promotes quality, strict management ensures safety", "traditional folk customs cast classics, twelve zodiac signs are crafted ingeniously", "promote ancient architectural culture, spread the wisdom of the Chinese nation", "small craftsmanship, quintessence of the country, spreading, showing new glory", "science journey of ideological and political practice of college students in the new era", etc. They run the concept of "strengthening moral education and cultivating people" through engineering education and popular science practice to improve students' engineering, professional, and humanistic qualities, and enrich the scientific and cultural life of college students.

\subsection{Carrying out Grass-roots Activities Under Science and Technology}

Xinjiang colleges and universities organize science and technology teams to go down to the grassroots level, and send the latest agricultural production and processing technology and the most intimate science popularization services to the grassroots to further strengthen the popularization of science. Aiming at the problem of the lagging application of agricultural production mechanization, they carry out popular science publicity and education, create a strong atmosphere of love and use of science, encourage them to change production methods through refined production methods. In 
response to the needs of mechanized and automated production and processing in grassroots agricultural production, they guide them to introduce highefficiency production equipment, enhance primary processing capabilities, increase the added value of agricultural products, and promote income and wealth. In response to the urgent technical needs reported by the grassroots, the scientific research team in the field of engineering in colleges and universities has developed a series of agricultural production machinery and equipment to promote the in-depth integration of production, education, research and use, and help the revitalization of the countryside.

\subsection{Carrying out Preaching and Education Activities}

According to the arrangements of the Chinese Association for Science and Technology and the Ministry of Education on the promotion of scientific ethics and style of study construction, the district has started the promotion and education activities of scientific ethics and style of study since 2011. At the launching ceremony of the publicity education activities for the construction of scientific ethics and style of study in Xinjiang and the first university presentation report meeting, three well-known experts from information engineering, mechanical engineering, and water conservancy engineering explained the true meaning of scientific ethics and the importance of the construction of the style of study, and advocated that the majority of scientific and technological workers abide by academic norms and adhere to academic integrity with a rigorous scientific attitude. A new chapter has been opened in the publicity and education activities of scientific ethics and style of study. In addition to centralized preaching, Xinjiang universities and colleges are based on actual conditions, and in accordance with the requirements of full coverage, institutionalization, and practical results, they carry out centralized preaching and education activities for newly enrolled graduate students. Later, the target of preaching education activities was gradually expanded to senior undergraduates and young teachers, preaching scientific spirit, scientific ethics, scientific ethics and scientific norms, forming a long-term preaching and education mechanism, and promoting the construction of scientific ethics and style of study to be deeply rooted in the hearts of the people.

\section{EXISTING SHORTCOMINGS}

\subsection{Vague Definition of Science Popularization Activities}

Some colleges and universities have not incorporated science popularization education into their important daily work, and the science popularization atmosphere is not strong, and the publicity is not in place. This has caused many teachers and students to confuse the concepts of science and technology activities and science popularization activities. In fact, there is a fundamental difference between the two. Scientific and technological activities refer to all systematic activities closely related to the production, development, dissemination and application of scientific and technological knowledge in various fields of science and technology. Scientific and technological activities are social activities. Science popularization activities refer to activities that make the use of various media in a simple and easy-tounderstand manner to make the public accept the knowledge of natural science and social science, promote the application of science and technology, advocate scientific methods, disseminate scientific ideas, and promote the spirit of science. Science popularization is a kind of social education. Due to the unclear definition, the science popularization and the dissemination of science and technology are mixed together, which makes the science popularization activities deviate from the theme and affects the effectiveness of the science popularization activities.

\subsection{The Role of Science Popularization Base Is Not Significant}

There are 54 colleges and universities in Xinjiang, of which 18 have established science and technology associations, accounting for only one-third. There are many engineering museums, laboratories, and engineering research centers that are open to teachers and students on campus. There are not many open to the public, the breadth and depth of social participation is not enough, and there are few creative popular science activities. There are 79 popular science bases in the autonomous region recognized by the Xinjiang Association for Science and Technology, of which there are 3 universities in Xinjiang. The number is relatively small. There is no science popularization base in the autonomous region for engineering subjects. It is urgent to strengthen the construction of science popularization bases and 
improve the level and level of science popularization bases in colleges and universities.

\subsection{The Results of Popular Science Are Not Well Displayed}

Since the beginning of the new century, Xinjiang's colleges and universities have published a series of popular science books for children of "Little Doctors' Roaming the Kingdom of Science", and the readers have received enthusiastic responses. The published reportage "Pointing the Earth and Asking the Universe-Commemorating the 120th Anniversary of Li Siguang's Birth" won the region's popular science work award, but in recent years, the popular science books of engineering have been seldom known. According to CNKI database retrieval with popular science as a key word, a total of 20,553 popular science literatures have been published nationwide since January 2016, including theses, works and dissertations, and 77 popular science literatures written by authors of Xinjiang. Among them, universities have written 16 popular science literature, including 6 theses and 10 dissertations. The popular science literature produced by universities accounts for $21 \%$ of Xinjiang's popular science literature, which does not match the popular science resources owned by universities. The papers have insufficient systematic and comprehensive research on the hot and difficult issues in the practice of science popularization, and cannot effectively provide scientific method and mechanism support for popular science activities.

\section{SCIENCE POPULARIZATION EDUCATION AND PRACTICE EXPLORATION}

\subsection{Intensifying Popularization of Science}

Science popularization propaganda is an ideological, scientific, and public welfare work. Xinjiang colleges and universities should actively learn from the advanced experience of colleges and universities of other regions in China in science communication, and use platforms such as WeChat, APP, and websites to extensively carry out social, mass, and regular scientific popularization activities with rich content and various forms to make the science popularization easy to understand and deeply rooted in the hearts of the people. It is necessary to give full play to the intellectual advantages of colleges and universities, encourage and guide teachers and students to develop popular science books, express high-tech cutting-edge engineering technology in popular and vivid language, so that readers can understand and read thoroughly, and promote the spirit of science and popularize science knowledge, carry out changes in customs, and promote the effects of the new fashion of the times.

\subsection{Carrying out Science Popularization Research}

Study of science popularization is a comprehensive discipline that is born from the intersection of natural sciences, social sciences, and humanities. Study of science popularization in a broad sense is a comprehensive discipline that conducts overall research on popular science with practice, experience, and methods. Xinjiang colleges and universities have great advantages in popular science research. Most schools have natural sciences, social sciences and humanities. It is a necessity to actively strive for funding for popular science research through multiple channels, organize teachers and students to carry out research on popular science innovation and practice, explore the use of information technology to develop and innovate popular science products, produce popular science products that integrate science popularization, innovation and interest, and improve science popularization timeliness and coverage to allow the scientific research results of colleges and universities to benefit ordinary people.

\subsection{Strengthening the Practice of Science Popularization Education}

The forms of popular science education are everchanging, and the characteristics of science popularization education are easily fascinating and deeply rooted in the hearts of the people. The practice of science popularization is not only an innovation in popular science theory and practice, but can more effectively improve the cultivation and improvement of the public's scientific quality. Science popularization education must advance with the times, reflect the characteristics of the times, and take participation as the main goal, so that science popularization practice education can have vitality and influence. It is necessary to actively explore new models of science popularization education and form a new education model combining "science popularization" + "engineering training" + "innovation and entrepreneurship". It is also necessary to establish a digital science education resource library, make full use of virtual simulation technology, teach students in accordance with their aptitude, precisely popularize science, and expand the 
pertinence and scientific nature of science popularization education.

\subsection{Strengthening the Construction of Science Popularization Base}

Science popularization bases generally refer to venues, facilities or places that rely on teaching, research, production, and service institutions, open to the society and the public, and have specific functions of science and technology education, dissemination, and popularization. The science popularization base is an important carrier of science popularization education, and it bears the important task of advocating scientific methods and disseminating scientific ideas. Xinjiang colleges and universities engineering majors have many multilevel laboratories, engineering research centers, and technology transfer centers. They can fully tap its science popularization resources, apply for approval to enter district-level or national-level science popularization bases, popularize scientific research results of collaborative innovation to the society, and let science popularization activities go out of campus and into the society, and be presented through rich and diverse science popularization methods.

\subsection{Strengthening the Construction of Science Popularization Team}

Xinjiang colleges and universities should scientifically construct a reasonable full-time and part-time science popularization talent echelon, establish a benign science popularization incentive mechanism, and combine scientific research with solving practical engineering problems and carrying out popular science education activities to form a high-level science popularization team that combines professional and science popularization education. The team includes both young and middle-aged backbones who are good at science and technology research and development and science popularization, as well as old "craftsmen" masters who understand modern engineering background and are good at guiding science popularization practices. They can tutor science popularization objects within their ability, so that the public can feel the development and charm of science and technology and engineering.

\section{CONCLUSION}

It is a long-term and arduous task to carry forward the scientific spirit, disseminate scientific thoughts and popularize scientific knowledge. Strengthening science popularization is an urgent need for higher education and economic and social development, as well as an important measure to implement the new strategy of rejuvenating science and education. Colleges and universities in Xinjiang should accurately grasp the responsibilities of popularizing science in the new era, and carry out a series of popular science activities with professional characteristics based on their own popular science resources, so as to promote the development and sharing of educational popular science resources, promote the dissemination and popularization of scientific thoughts, scientific spirit, scientific methods and scientific knowledge, and improve the scientific quality of the whole people.

\section{AUTHORS' CONTRIBUTIONS}

Yan Ma was in charge of writing the paper, Wenjing Teng was in charge of data statistics and paper modification, and Lijuan Jin participated in the writing of the paper.

\section{REFERENCES}

[1] Ni Minghui, Zhang Liucheng, Li Nan, The Optimal Construction of Innovation and Entrepreneurship Education Mode under the Integration of School and Enterprise [J]. Foreign Economic Relations \& Trade, 2020(10): 145148. (in Chinese)

[2] Wang Huilin, Liang Zhijuan, Research on the Current Situation of Science Popularization Activities in Colleges and Universities [J]. Science \& Technology Vision, 2020(30): 1-4. (in Chinese)

[3] Zhang Shilin, The Predicament and Breakthrough of Popular Science Practice in Colleges and Universities [J]. Encyclopedic Knowledge, 2020(21): 17-19. (in Chinese)

[4] Wang Yanhua, Qiao Peng, Xu Weijie, Shu Ganping, Wu Gang, Strengthening the Construction of Popular Science Bases to Improve the Social Service Function of Colleges and Universities [J]. Research and Exploration In Laboratory, 2020, 39(2): 254-257+307. (in Chinese)

[5] Jiang Yu, Chen Chaoshu, Qin Cailian, Qin Yingfeng, Chen Chaojie, Discussion on Popularizing Educational Modes in Colleges and Universities [J]. Education Teaching Forum, 2019(25): 119-120. (in Chinese) 
[6] Yan Xinxin, Innovating the Methods and Ways of Popularizing Social Science in Colleges and Universities [J]. Inner Mongolia Scientech and Economy, 2019(5): 23-24+31. (in Chinese)

[7] Liu Xiaodong, Ma Cong, Jiang Lingfu, Discussion on Popular Science Work in Universities [J]. Science \& Technology Association Forum, 2014(5): 21-24. (in Chinese)

[8] Liu Yinong, Hu Hang, Liu Erwen, Ni Wenhao, $\mathrm{Li}$ Xinpei, $\mathrm{Li}$ Sha, Problem and Countermeasures of the Mode of University Popular Science Education [J]. Journal of Shandong Jianzhu University, 2014, 29(4): 392396. (in Chinese) 